\title{
Study of the level of awareness of the Iraqi society to the Impact of climate changes
}

\author{
Ahmed Hasson ${ }^{1}$, Saad KH. Mahmood Aljumaili ${ }^{2}$ \\ ${ }^{1}$ Mechanical Engineering Department, College of Engineering, Alnahrain University, Baghdad, Iraq \\ ${ }^{2}$ Architecture Engineering Department, College of Engineering, Alnahrain University, Baghdad, Iraq
}

\section{Email address:}

am.hasson2@gmail.com (A. Hasson), aljumaily.saad@ymail.com (S. KH. M. aljumaili)

\section{To cite this article:}

Ahmed Hasson, Saad KH. Mahmood Aljumaili. Study of the Level of Awareness of the Iraqi Society to the Impact of Climate Changes. American Journal of Environmental Protection. Vol. 3, No. 5, 2014, pp. 258-262. doi: 10.11648/j.ajep.20140305.18

\begin{abstract}
Baghdad is a large city, warmer than surrounding areas due to the urban heat island effect. This research is to understand what Iraqi society segments thought about issues represented a tangible threat to their urban environment and lifestyle. Questions were establish what scholars, student and Architect thought about the impact of climate change and UHI. Analysis indicated that there was a moderated acceptance in society segments, students, scholars and low among the urban residents of Iraqi society that complex issue such as Urban Heat Island as part of climate change was occurring and an even lower acceptance that it was the result of human activity. Nonetheless, the low acceptance reflected a high degree of uncertainty among urban people rather than widespread open skepticism. The uncertainty among urban residents could be attributable to scientific discrepancies about causes of Urban Heat Island and the possible consequences. The results show that trust in science and scientific credibility has been undermined by these discrepancies and the perception that scientists are using climate change to pursue their own agendas. With only $52 \%$ of educated survey respondents believing that climate change and Urban Heat Island information were easy to understand, there was a clear need to reconsider communication strategies for the dissemination of scientific information in universities and institutes. Results indicate that minimal adaptive responses of Iraqi society to changes in local climate, current and past extreme changes in Iraqi urban temperature, water scarcity and dust storm seasons support results that indicate society did not prioritize Urban Heat Island imperative. Generally, well-educated community did not recognize or underestimated the short to medium term risk Urban Heat Island represented for their urban environment or lifestyles.
\end{abstract}

Keywords: Ethics, Community, Uncertainty, Credibility, Climate Change, Urban Heat Island, Extreme Climate

\section{Introduction}

Chief among the ethical implications for extreme weather is the global nature of the problem. Among these drawbacks are the possibility of the principal impact of climate change on Iraqi cities are associated with dusts toms and severe weather.

Trees can reduce air-conditioning use through a decrease in ambient temperature, thereby reducing ozone production and greenhouse gas emissions.

Strategically planted vegetation decreases energy use in three ways. First, shading windows helps prevent direct solar radiation from entering a building. Second, the tree will reduce the amount of radiation hitting the roof and walls, reducing the amount of radiation reaching the structure. Last, shading affects the energy use by cooling the soil around the house that can act as a "heat sink" for the house.
The university of Alnahrain team noted how the actions of one educated person in Iraqi could affect people in other Iraqi society segments, and it is these people that are at the greatest risk, but have little control over how those in developed countries respond to protect their wellbeing. Society must take into consideration these perspectives and accept moral responsibility based on the team questioner data analysis.

Climate change has become a global issue in recent times manifesting in variations of different climate parameters including cloud cover, precipitation, temperature ranges, sea levels and vapor pressure [1]. The variations in climate parameters affect different sectors of the economy such as agriculture, health, water resources, energy etc. The principal cause of climate change has been attributed to anthropogenic (human) activities.

The relatively dry and variable climate that in Iraq and the 
region are conducted under, has resulted in educated and farmers from those regions developing a context and specific knowledge of local conditions and management strategies to successfully contend with the variability of prevailing conditions [2] - [3]. Although pronounced changes in local climate as a result of climate change have occurred [4], memory often defines perceptions of the current situation and as a result there may be a lag time between acceptance of the evidence [5]. In addition, local knowledge concepts formed within Iraqi society' social, economic and environmental constructs could also lead to conflict with scientific knowledge [5,6]. This may result in rejecting part or all of the available scientific information necessary for adaptation.

Colleges and universities are being embroiled in these developments, requiring strategic planning to be undertaken immediately. As an aid to those campuses starting such planning, we include here a brief critique of the increasingly dangerous nature of climate change and the corresponding legislative and regulatory principles that are being put in place and that will affect higher education institutions.," we indicate how achieving knowledge efficiency using campus cyber infrastructure to deal with climate change can help meet some of the current and future Iraqi society opinions.

To provide high quality of academic programs of consistency with scientific and technological development at the local, regional and global institutions. Furthermore, delivering an effective participation in the progression of techniques and continuous improvement in the educational research system through the collaboration with the entities working to the demands of the labor market.

Educated and rural communities are key decision-makers in the process of Iraqi society's adaptation in the face of accelerated climate change. Climate change has taken center stage in global diplomacy. If scholar, students and farmers do not believe that climate change is occurring or believe that the changes in climate are part of a normal climatic cycle, they may fail to adequately adapt. The resilience of associated educated people and society systems to the impacts of climate change could be severely undermined, shifting to a less satisfactory phase state. Poor adaptation and low sustainability of university scholar and students would not only severely impact on the knowledge performance of the future climate change extension education but could also cause serious social disintegration throughout Iraqi communities.

The objectives of the research are to understand what students, scholars and urban residents thought about, climate change science and Urban Heat Island and the associated outcomes. Perceptions and decisions that contribute an influence were identified.

The uncertainty among Iraqi community could be attributable to scientific discrepancies about causes of climate change and the potential outcomes

\section{Methods}

This study argued that the level of people's familiarity with an activity defined their tolerance or averseness of risk associated with the activity. The higher the level of familiarity with an activity, the higher the level of risk tolerance exhibited.

The research team asked questions to establish what scholars, student, Architect and commuters thought about climate change and the potential impacts.

- Did scholars, students and commuters think?

- Question 1. That climate change was coming?

- Question 2. That Urban Heat Island, UHI was natural or influenced by human activity?

- Question 3. That UHI represented a tangible threat to their lifestyle?

In addition, the research questioned:

- Whether perception of science and governance was influencing people's attitudes?

- Other factors were contributing to the development of attitudes and opinions?

- What identified the different groups of responses to climate change?

The inquiry sought to determine if climate change skepticism was present in educating peoples' communities at levels that could undermine pro-active adaptation. It draws on both quantitative and quality methods of data collection to examine the perceptions that educated people have of climate change.

The qualitative study was undertaken before the quantities research using semi-structured in-depth interviews with a small number of the university scholar and students. This research was conducted to ensure that all relevant variables were included in the survey. The main body of the research was carried out using a structured survey instrument. The survey was conducted primarily via personal intercepts during the days between June 2013 and March 2014. The particular levels of students and scholars were chosen from the faculty of engineering and faculty of sciences, the university of Alnahrain, Baghdad and scientific research center, Baghdad because they afforded access to large numbers of potential issues as well as being representative of the diversity of educated levels and study regions and climate that comprise education industrial sectors of Iraq. To ensure representation of a breadth of suburbs foundation, additional surveys was carried out at residents in southern suburbs of Baghdad. There were a total of 547 responses in the survey. Of these; 245 were students, 24 scholars, staff were 110,169 represented the broader local resident community and 49 were represented small business. Analysis was primarily undertaken using Numerical analysis based on SPSS (Statistics Package Software ) .The data were collected and manipulated according to their frequencies .Since the sample sizes of the subgroups are irregular the percentage method is used.Three points Likert scale with weighted mean then employed to indicate the response sense. The reliability and validity of the measurements were also checked by evaluating coefficient of Cronbach's Alpha This approach takes full advantage of computer-based approaches to provide a more statistically reliable outcome. It does not take a normal distribution of data does not exclude outriders from the data and is not dependent 
on a priori conclusions about the importance of specific variables (dependent and independent variables) in defining the clusters, ordination or networks. The analysis simultaneously assesses relationships between characters and variables to portray value relationships through clustering, ordination, networks and statistical evaluation [7].

\section{Results and Discussion}

Results include urban resident's attitudes to climate change, urban Heat Island, UHI and governments' role

Iraqis needs real domestic action on climate change. In this investigation four social segments are considered namely: scholar, students, residents and Architect with 547 of observations size.

\subsection{Social Attitudes to Climate Change}

Initial analysis suggested lack of consistency between Iraqi community' (students, scholar architect and residents) attitudes to changes in their local climate and their opinions about global climate change and what has caused it. Generally the Iraqi community acknowledged that they had noticed a decrease in rainfall, increase in seasonal variability and to a lesser extent more frequent extreme weather events (such as severe high temperatures and dust storms). Many people from university indicated that they were not concerned that rainfall had decreased as less rain had eased water logging issues and resulted in improved grain yields. On the other hand, seasonal variability was a concern for farmer's community people.

Despite the recent prolonged the climate change occurring, more urban' community $(70 \%)$ believed that poor seasons and seasonal variability were a normal seasonal process compared to the university community (scholar and students), 0 and $2 \%$ respectively shown in Table 1.

Table 1. I recognized that Urban Heat Island as part of climate change is occurring.

\begin{tabular}{|c|c|c|c|c|c|c|c|}
\hline \multirow{3}{*}{ Groups } & \multicolumn{6}{|c|}{ Frequency and ratio } & \multirow{3}{*}{ Size } \\
\hline & \multicolumn{2}{|c|}{ Agree } & \multicolumn{2}{|c|}{ Uncertain } & \multicolumn{2}{|c|}{ Disagree } & \\
\hline & $\mathbf{N}$ & $\%$ & $\mathbf{N}$ & $\%$ & $\mathbf{N}$ & $\%$ & \\
\hline Scholar & 24 & 100 & 0 & 0 & 0 & 0 & 24 \\
\hline Students & 230 & 92.63 & 9 & 3.15 & 6 & 2.1 & 245 \\
\hline Architect & 94 & 85.29 & 10 & 8.82 & 6 & 5.88 & 110 \\
\hline Residents & 13 & 8 & 37 & 22 & 118 & 70 & 168 \\
\hline
\end{tabular}

People from university (scholar and students) and the urban's community were high inclined to accept that the observed changes in local urban climate were related to climate change (Table 2).

There was however, a less level of uncertainty that poor seasons and climate change was associated with about $33 \%$ of students and $50 \%$ of urban's community indicating indecision (Table 2). Low levels of uncertainty were an underlying theme to responses UHI related to climate change through the research.
Table 2. The ratio and frequencies to each group fear of human-made global climate change \&UHI.

\begin{tabular}{lccccccc}
\hline & \multicolumn{6}{c}{ Frequency and ratio } & \\
\cline { 2 - 6 } Group & \multicolumn{2}{c}{ Agree } & \multicolumn{2}{c}{ Uncertain } & \multicolumn{2}{c}{ Disagree } & \multirow{2}{*}{ Size } \\
\cline { 2 - 6 } & $\mathbf{N}$ & $\%$ & $\mathbf{N}$ & $\%$ & $\mathbf{N}$ & $\%$ & \\
\hline Scholar & 22 & 91.6 & 0 & 0 & 2 & 8.33 & 24 \\
Students & 173 & 50.5 & 28 & 31.57 & 44 & 17.89 & 245 \\
Architect & 76 & 49.1 & 15 & 33.23 & 19 & 17.6 & 110 \\
Residents & 87 & 12 & 17 & 50.4 & 64 & 38 & 168 \\
\hline
\end{tabular}

Overall, more than $53 \%$ of all communities surveyed accepted that UHI was happening and $61 \%$ believed that it was human-caused. There was a small variation across the three community groups (Tables 3 and 4).

Table 3. I believe that climate change represents a palpable threat to Urban Heat Island and lifestyle.

\begin{tabular}{cccccccc}
\hline \multirow{2}{*}{ Group } & \multicolumn{6}{c}{ Frequency and ratio } & \multirow{2}{*}{ Size } \\
\cline { 2 - 7 } & \multicolumn{2}{c}{ Agree } & \multicolumn{2}{c}{ Uncertain } & \multicolumn{2}{c}{ Disagree } & \\
\cline { 2 - 7 } & $\mathbf{N}$ & $\%$ & $\mathbf{N}$ & $\mathbf{\%}$ & $\mathbf{N}$ & $\%$ & \\
\hline Scholar & 19 & 81.3 & 4 & 16.7 & 1 & 2.0 & 24 \\
Students & 206 & 84 & 17 & 7 & 22 & 9 & 245 \\
Architect & 102 & 92.64 & 3 & 2.4 & 5 & 5 & 110 \\
Residents & 25 & 15 & 32 & 19 & 111 & 66 & 168 \\
\hline
\end{tabular}

The low acceptance among the community of climate change occurring and that it was caused by man activities were reflected in responses to the economic importance of climate change in comparison to another pressures in their businesses (Table 4).

Overall Iraqi community acknowledged that climate change was of some UHI and economic importance but short term economic imperatives such as fuel, and fuel prices took precedence. Educate people discussion meeting presumed that climate change was an extension of bad seasonal variability which is not incorporated into management strategies by authorities.

Table 4. Economic importance to urban's business sustainability.

\begin{tabular}{lccc}
\hline Status & Agree \% & Disagree \% & Uncertain \% \\
\hline Scholars & 91.7 & 4.2 & 4.2 \\
Students & 90.0 & 5.0 & 5.0 \\
Architects & 92.2 & 7.8 & 0.0 \\
Overall & 91 & 6 & 3 \\
\hline
\end{tabular}

\subsection{Adaptive Measure in the Effects of Climate Change on} UHI

The most significant adaptive measures adopted by residents in coping with climate change effects in the study area are presented in Table 5. These include; increase in community services $(61.4 \%)$, insect resistance verities $(73.6 \%)$ long-term scarcity of water for human and irrigation use 
(88\%), shortage in electricity and fuel consumption $(85 \%)$. Other useful adaptive measures adopted include healthcare to $55 \%$. On the air-conditioning materials, items $25 \%$ to $55 \%$ were not regarded as significant adaptation measures in the country.

Table 5. Distribution of respondents based on the adaptive measures adopted. $(N=168)$.

\begin{tabular}{llc}
\hline Adaptive measures Percentage & Level & $\%$ \\
\hline Increase in mechanical equipment's & Some & 27.9 \\
Air conditioning schemes \& maintains & Some & 25.0 \\
Healthcare & Quite a bit & 55.0 \\
Insects resisted varieties & Important & 73.6 \\
Community services requirements & Important & 61.4 \\
Shortage in drinking \& irrigation water & Very important & 88.0 \\
Shortage in power and fuel prices & Very important & 85.0 \\
\hline
\end{tabular}

The increase in urban soil salinity and water scarcities \& pollution provides useful adaptations and resilience to the effects of climate change. Such trees destruction is known to survive and complete their life cycles normally even when the environment will not allow others to flourish. The increased adoption of resistant varieties/species may not be unconnected with the fact that residents encounter serious pest and disease infestations and weed growth, which have been acknowledged as the most significant effects of climate change in the region. It has already been reported that one of the many adaptations to climate change involves the use of resistant varieties such as early maturing varieties or drought resistant ones. Nevertheless, residents noted that the issue of availability of the resistant varieties at the appropriate time is a problem. This has led them to once in a while fall back to local species that might fall victim of the environmental changes. It was reported also that the non-availability of seeds may be a significant impediment to adaptation [8]. Educated people noted that with the increase in temperature and evapotranspiration resulting from climate change, measures to conserve moisture for urban green landscape use is necessary, hence they preferred the use of organic manure. Mixed farming practice is adopted by residents for many reasons such as to ensure green landscape security, increased trees, reduced incidence of pests and diseases, among others.

Developed countries, all urban residents confirmed that they engaged in mixed practice to confront UHI. In response to higher temperatures, urban residents have resorted to using heat tolerant with high water use efficiency, in contrast, the poor government policy of the import agricultural crops leads to a negative impact on Iraqi farm production.

\subsection{The Scale Reliability}

The reliability coefficient of Cronbach's Alpha is considered to be "acceptable" when it is about $70 \%$ or higher in most social science). Researchers [9] (Table 6), shows the result of such a test for the current study which is $89 \%$.The validity of the measurement (which is the square root of
Alpha) is found at $94 \%$ which is higher, too.

Table 6. Reliability coefficients.

\begin{tabular}{cccc}
\hline N of Cases & N of Items & Alpha & Validity \\
\hline 597 & 3 & .89 & 0.94 \\
\hline
\end{tabular}

Table 7 indicates the respondent means to the questions for each individual group as well as for the total sample. In this table the weight means of the three questions were calculated according the triple Likert scale .In this calculation Disagree, Don't know and Agree are assigned weights mean values as 1,2 and 3 respectively .Finally, The attitude can be assessed by comparing the calculated means with the corresponding scale interval .The scale intervals for the triple Likert are as the following: Disagree between 0 and 1.66, Don't know between 1.67 and 2.33 and Agree between 2.34 and 3. The attitudes of the groups are evaluated and collected in a Table (8).

Table 7. The respondent weighted means of the groups.

\begin{tabular}{lccc}
\hline Group name & Q-1 & Q-2 & Q-3 \\
\hline Scholars mean & 3.00 & 3.00 & 2.75 \\
$\mathrm{~N}$ & 24 & 24 & 24 \\
$\mathrm{SD}$ & 0.00 & 0.00 & 0.532 \\
Students' mean & 2.91 & 3.00 & 2.75 \\
$\mathrm{~N}$ & 245 & 2.45 & 245 \\
$\mathrm{SD}$ & 0.358 & 0.00 & 0.607 \\
Architects mean & 2.80 & 3.00 & 2.88 \\
$\mathrm{~N}$ & 110 & 110 & 110 \\
SD & 0.521 & 0.00 & 0.444 \\
Residents mean & 1.37 & 2.13 & 1.49 \\
$\mathrm{~N}$ & 169 & 169 & 169 \\
SD & 0.624 & 0.942 & 0.74 \\
Totals mean & 2.36 & 2.67 & 2.38 \\
$\mathrm{~N}$ & 547 & 547 & 547 \\
SD & 0.865 & 0.719 & 0.866 \\
\hline
\end{tabular}

Table 8. The attitudes of the groups.

\begin{tabular}{cccccc}
\hline & Scholar & Students & Architect & Residents & All \\
\hline Q1 & Agree & Agree & Agree & Disagree & Agree \\
Q2 & Agree & Agree & Agree & Don't know & Agree \\
Q3 & Agree & Agree & Agree & Disagree & Agree \\
\hline
\end{tabular}

Research shows that most Iraqi community does not feel a personal connection to UHI. They are aware of it, they may even rank it as a business, but they do not perceive it as a near-term priority on par with, say, the economic downturn or the need to reform infrastructure services such as electricity or job availability. In fact, despite scientists' calls for urgent action, climate change has slipped to the bottom of the list of Iraqis priorities.

The uncertainty among Iraqi community could be attributable to scientific discrepancies about causes of climate 
change and the possible consequences. The results show that trust in science and scientific credibility has been undermined by these discrepancies and the perception that scientists are using climate change to pursue their own agendas. We believe that climate change information was easy to understand, there was a clear need to reconsider communication strategies for the spreading of scientific information in universities, colleges and the community as whole.

Residents' attitudes that climate change was not a priority risk were reflected in their responsiveness to adaptation. In response to changes in their local climate $92 \%$ of farmers were initiating a high level of change in their management practices, and economic slump. There had not implemented any enterprise. (Table 8). The severity of past poor seasons did not appear to influence adaptive responses to all Iraqi society segments.

The severity of heat and dusty seasons did not appear to influence adaptive responses. However the following comment from a broader community perhaps summarizes the effects of adaptation that confront community people. "residents cannot react in a healthy way to climate changes if the short or long term sustainability is unhealthy." This response reflects a scientist's observation that for environmental sustainability innovation to be adopted, the community needs the innovation to meet viable physical and economic criteria. However these responses should not be interpreted as broad climate change skepticism among some educated people and most Iraqi society.

\section{Conclusions}

Conclusions from our country universities conferences seminars study highlight the need for increased understanding of the urban heat island impacts of climate change at the regional level,

- Economic impacts of urban heat island will occur throughout the cities.

- Economic impacts will be unevenly distributed across the Middle East region and within the economy and society of the cities.

- Negative climate impacts will outweigh benefits for most sectors that provide essential

- Urban Heat Island, UHI impacts will place immense strains on public sector budgets.

- Secondary effects of UHI can include raise health problems, reduced income and job losses

Among these drawbacks are the possibility of the principal impact of UHI on Iraqi cities are associated with high air temperature.

Comparative, ethical perspective is necessary to wade through a debate that is largely scientific in nature. Thinking in terms of morality and ethics is vital given the grave implications of the issue. "The ethical dimensions should be obvious because the consequences are so huge."

\section{Acknowledgements}

Support was provided by the College of Engineering, Alnahrain University, the scholars, engineers, residents of southern Baghdad, College of Science, and the Ministry of Science \& Technology.

\section{Reference}

[1] United Nations, 2012Climate Change in Iraq Fact Sheet,..

[2] Morgan, L Climate Change and Adaptation in South West Western Australia: Community, industry and gov ernment views on past and future climate change for WA: DAF, Bulletin 47062006.

[3] Essen, S A 2008 Virtual laboratory of the Northern Agricultural Region, Special CAP project, Agricultural Research WA Climate Adaptation Program Prospectus, version 2. DAFWA.

[4] Cram, J 2008 How our temperatures have changed. Bureau of Meteorology, Perth .Retrieved on 10 February from www.ioci.org.au.

[5] Stedman, R. 2003"Is It Really Just a Social Construction?: The Contribution of the Physical Environment to Sense of Place." Society and Natural Resources 16, 671-685.

[6] Vanclay, F 2009 Social principles for agricultural extension to assist in the promotion of natural resource manage ment.' Australian Journal of Experimental Agriculture 44, 3, 213-222. $\begin{array}{llll}\text { Retrieved on } 6 & \text { March } & \text { from }\end{array}$ www.publish.csiro.au.dgbw.lis.curtin.edu.au(2004.

[7] Wardell-Johnson, 2005 A Social relationships in landscape systems: identifying values and variables that drive social interactions. Systems Thinking and Complexity Science: Insights for Action: 11th Annual ANZSYS Associa tion of British Insurers.

[8] Barnett, T.P. 1984 The estimation of sea level change: a problem of Uniqueness', Journal of Geophysical Re search, 89: 7980-7988.

[9] Hogg, M and Vaughan, G. 2005 Social Psychology, London, Prentice Hall, 4ed. 